\title{
Gedichte und Erzählungen
}

\author{
Erhard Taverna
}

\section{L'Orpailleur}

Der 1953 geborene Mediziner Claude André Dessibourg und der Künstler Claude Luezior haben das Privileg, als ein und dieselbe Person erfolgreich in zwei verschiedenen Welten zu leben. Der eine als Neurologe und Lehrbeauftragter an der Universität, der andere als mehrfach ausgezeichneter Schriftsteller, Romanautor und Lyriker.

Der schmale Gedichtband L'Orpailleur (Der Goldwäscher) fällt durch seine pointierte, aphoristische Sprache auf, die gedrängt und prägnant von der Liebe zu Menschen spricht. In einer Welt der Unmenschlichkeit kämpft Luezior gegen unsere Gleichgültigkeit, indem er scharfzüngige Barrikaden errichtet, schützende Wortdämme und Sprachinseln des Trostes. An Stelle von Überschriften umschreibt er thematisch den Gedanken, den er nachfolgend mit knappen Worten vertieft und weiterführt. Diese Bemerkungen sind ihm Programm und Motiv seines Schreibens: «Pourquoi ma feuille blanche a-t-elle soif de tant de souffrance? Ecrire avec la douleur des autres, est-ce bien raisonnable? Pour que cette douleur ne soit pas tout à fait inutile.»

Seine Epigramme können auch witzig und ironisch sein: «Allons enfants de la patrie Acceptons ceux d'une autre patrie - Ceux qui n'en ont plus - Ceux que nous comptables refusent - Notre jour de tolérance est arrivé.»

Luezior nimmt es sehr genau mit der Sprache. Denn er weiss um die Macht des Wortes.

Dans les dédales
De l'orgueil
Et les cortèges
Barbares
Ou trébuchent
Les ivrognes
Du langages
Nous avons déposé
Ce mot
Nouveau-né
Bien rose
Qu'ils tenterons
De crucifier
Sans doute
Ce mot
Sans fard
Ni lutte
D'influence
Ce mot

Tout nu

Qu'ils oublierons

De baptiser

Ce mot

Qu'on appelle

Parfois

Aimer

Claude Luezior. L'Orpailleur.

Poèmes et aphorismes.

Paris: Edition L'Harmattan; 2002.

\section{Totentanz}

Flavio Daniele Sepulcri, 1953 geboren, Internist und Kardiologe, inszeniert einen Totentanz mit Variationen. 20 Kurzgeschichten thematisieren den Tod, witzig, frech, humorvoll, gelegentlich drastisch, immer unterhaltend, oft überraschend durch eine unerwartete Wendung oder eine Pointe. «Denn alles Interesse für Tod und Krankheit ist nichts als eine Art von Ausdruck für das Leben», zitiert der Autor Thomas Mann. Und wie das Leben vielfältig, so sind es auch die Erzählungen, die mit wenigen Worten eine dichte Atmosphäre schaffen und verzweigte Handlungsstränge gekonnt verknüpfen. Es sind Liebesgeschichten, Kurzkrimis, Krankengeschichten, Polizeiprotokolle, Legalinspektionen und Beerdigungen, skurril, traurig, ironisch, makaber. Sepulcri ist ein guter Beobachter und Menschenkenner, der klinische Genauigkeit mit Fabulierlust und Sprachkönnen verbindet. Auch zu einem Totentanz wird aufgespielt. Elvis Presley singt den «Jailhouse Rock» und Richard Strauss" «Vier letzte Lieder» begleiten den Freitod. Dem Schweigen am Ende geht die Musik voraus. Sepulcri komponiert das Thema des Todes in den vielfältigsten Variationen, als wären seine Geschichten eine Partitur, die unzählige Lebensthemen dem unvermeidlichen und dennoch einmaligen und unvergleichlichen Schlussakkord entgegenführt.

Flavio Sepulcri interessiert sich für Musik und Literatur. Er spielt Klavier und plant einen Roman. Der Anfang sei gemacht. Wir wünschen ihm viel dazu viel Erfolg.

Flavio Daniele Sepulcri.

Totentanz mit Variationen. Erzählungen.

Frankfurt/Main: Fischer \& Fischer,

Medien Aktiengesellschaft; 2003. 155 Seiten. 